Hubertus Pietsch

Philipp Lengsfeld

Gregor Jost

Thomas Frenzel

Joachim Hütter

Martin A. Sieber

\section{Long-term retention of gadolinium in the skin of rodents following the administration of gadolinium-based contrast agents}

Received: 24 July 2008

Revised: 7 November 2008

Accepted: 19 November 2008

Published online: 24 January 2009

(C) The Author(s) 2009.

This article is published with open access at Springerlink.com

\author{
H. Pietsch - G. Jost - T. Frenzel • \\ J. Hütter · M. A. Sieber $(\bowtie)$ \\ Bayer Schering Pharma AG Contrast \\ Media Research, \\ Muellerstraße 178, \\ 13353 Berlin, Germany \\ e-mail: martin.sieber@bayerhealthcare. \\ com \\ Tel.: +49-30-46814439 \\ Fax: +49-30-46894439 \\ P. Lengsfeld \\ Global Medical Affairs Diagnostic \\ Imaging, Bayer Schering Pharma AG, \\ Berlin, Germany
}

\begin{abstract}
Several publications suggest a potential association between the administration of Gadoliniumbased contrast agents (GBCAs) and the onset of a rare but serious disease, Nephrogenic Systemic Fibrosis
\end{abstract} (NSF). The aim of this study was to determine the elimination time-course of Gadolinium (Gd) from skin tissue after application of GBCAs in rats. Seven different marketed GBCAs were injected on five consecutive days at a dose of $2.5 \mathrm{mmol} / \mathrm{kg}$ bodyweight into the tail vein of Han-Wistar rats and the Gd concentrations were determined by Inductively Coupled Plasma Mass Spectrometry (ICP-MS) in skin biopsies taken at various timepoints up to a year after the last injection. Most of the administered Gd was eliminated from the skin within a time-period of about 2 months. How- ever, the repeated administration of linear GBCAs resulted in long-term retention of a small portion of the administered Gd in the skin tissue of rats, with substantially higher values observed in animals treated with nonionic linear agents than in those that received ionic linear GBCAs. Following treatment with macrocyclic GBCAs, Gd values in the skin were in the same range as observed in the controls from day 24 post-injection onwards. In summary, we observed a correlation between the complex stability of GBCAs and the amount of residual Gd in the skin up to a year after application of GBCAs.

Keywords Gadolinium-based contrast agents - Gadolinium retention . Skin · Nephrogenic systemic fibrosis . Stability

\section{Introduction}

Gadolinium-based contrast agents (GBCAs) used for Magnetic Resonance Imaging (MRI) contain a single paramagnetic $\mathrm{Gd}^{3+}$ ion tightly bound by a complexing agent. On the basis of the chemical structure, GBCAs can be divided into two distinct classes: the linear, open-chain agents and the macrocyclic agents [1]. Each class can be further divided into ionic and non-ionic agents. The different classes, as well as the different agents within each class, have different complex stabilities, i.e. propensities to retain the $\mathrm{Gd}^{3+}$ ion in the complex (Table 1).

The stability of GBCAs is characterized by two parameters, the kinetic inertia and the thermodynamic stability. Macrocyclic GBCAs are kinetically inert to $\mathrm{Gd}$ dissociation compared to linear GBCAs, as they possess a substantially higher kinetic stability, characterized by the dissociation half-life $[2,3]$. As the estimated dissociation half-life of macrocyclic GBCAs is over 1,000 years at $\mathrm{pH} \mathrm{7.4,} \mathrm{the} \mathrm{thermodynamic} \mathrm{stability} \mathrm{of} \mathrm{these} \mathrm{GBCAs,}$ characterized by $\log \mathrm{K}_{\text {therm }}$ and $\log \mathrm{K}_{\text {cond, }}$ is of minor relevance [3].

The linear GBCAs possess a comparatively lower kinetic stability. For the stability of these GBCAs, the thermodynamic stability is a more relevant factor. The non-ionic GBCAs, such as Omniscan and OptiMARK, have a substantially lower thermodynamic stability compared with the ionic GBCAs, such as Magnevist or MultiHance [3].

Several publications have suggested a potential association between the administration of GBCAs and a relatively 
new disease, Nephrogenic Systemic Fibrosis (NSF) [4, 5]. In articles based on preclinical studies we have conducted, we have reported a correlation between the Gd concentration in skin tissue and the occurrence of NSF-like skin lesions in rats $[6,8]$. In all such studies, we observed marked differences regarding the $\mathrm{Gd}$ concentration in various tissues of the animals after treatment with the different GBCAs. The most pronounced differences were observed in the skin. The highest Gd concentrations in skin tissue were observed after treatment with non-ionic linear GBCAs (Omniscan and OptiMARK). The lowest concentrations were observed after treatment with macrocyclic GBCAs (Gadovist and Dotarem) [7]. It is important to note that the measurement method (ICP-MS) used cannot distinguish between chelated and unchelated $\mathrm{Gd}$. This fact led to the hypothesis that at least part of the Gd measured 5 days post-injection (p.i.) may still have consisted of chelated Gd, which may potentially be eliminated from the body at a later time-point. Therefore, the aim of this study was to determine the elimination time-course of $\mathrm{Gd}$ in skin tissue and the potential long-term retention of $\mathrm{Gd}$ in the skin after application of different marketed GBCAs.

\section{Materials and methods}

Animals

Han-Wistar rats (CRL:WI [GIx/BRL/HAN]IGS BR) were obtained from Charles River (Sulzfeld, Germany), each weighing 210-346 g. The animals were housed with a $12 \mathrm{~h}$ day/night rhythm and were given water and standard diet (ssniff R/M-H from Sniff, Germany) ad libitum. Animals were treated according to the German law on the protection of animals and with permission of the state animal welfare committee.

\section{Study design}

Six animals for each treatment group were selected at random and were treated in three experimental sets. Omniscan (set 1), Magnevist (set 1), Gadovist (set 1), MultiHance (set 2), ProHance (set 2), Dotarem (set 2), and OptiMARK (set 3) and saline (set 3 ) were injected into a tail vein once daily on five consecutive days at a dose of $2.5 \mathrm{mmolGd} / \mathrm{kg}$ bodyweight (b.w.). An untreated group (set 1) was included as a second negative control group. Skin biopsies were taken from the backs of the animals at various time-points up to 364 days p.i. (please refer for the different time-points to Fig. 1) under 3.5-4\% isofluran inhalation with a biopsy punch (Biopunch $4 \mathrm{~mm}$, Stiefel Laboratorium GmbH, Offenbach Germany) and the wounds were sutured with Vicryl rapide (Ethicon GmbH, Norderstedt Germany).

Pharmacokinetics of GBCAs in rats

To assess the pharmacokinetic parameters of GBCAs, Omniscan, Magnevist, MultiHance and Gadovist were

Table 1 Key parameters of the chelates investigated in this study (n.a. no data available)

\begin{tabular}{|c|c|c|c|c|c|c|c|}
\hline \multirow[t]{2}{*}{ Trade name } & \multirow[t]{2}{*}{ Generic name } & \multirow{2}{*}{$\begin{array}{l}\text { Structural } \\
\text { class }\end{array}$} & \multicolumn{3}{|c|}{ Stability-related parameters relevant for linear agents } & \multirow{2}{*}{$\begin{array}{l}\mathrm{LD}_{50} \text { i.v. rat } \\
(\mathrm{mmol} / \mathrm{kg})\end{array}$} & \multirow{2}{*}{$\begin{array}{l}\text { Selectivity for } \\
\mathrm{Gd}^{3+} \text { over } \mathrm{Zn}^{2+} \\
\left(\mathrm{KGdL} / \mathrm{KZnL} \times 10^{-4}\right)\end{array}$} \\
\hline & & & $\begin{array}{l}\text { Thermodynamic } \\
\text { stability (log } \\
\left.\mathrm{K}_{\text {therm }}\right)\end{array}$ & $\begin{array}{l}\text { Conditional } \\
\text { stability (log } \\
\mathrm{K}_{\text {cond }}, \mathrm{pH} \mathrm{7.4)}\end{array}$ & $\begin{array}{l}\text { Excess free ligand in } \\
\text { formulation }(\mathrm{mg} / \mathrm{ml})\end{array}$ & & \\
\hline Omniscan & Gadodiamide & $\begin{array}{l}\text { Non-ionic } \\
\text { linear }\end{array}$ & 16.9 & 14.9 & 12 & $34^{\mathrm{a}, \mathrm{b}}$ & $7.9^{\mathrm{a}, \mathrm{b}}$ \\
\hline OptiMARK & Gadoversetamide & $\begin{array}{l}\text { Non-ionic } \\
\text { linear }\end{array}$ & 16.8 & 15.0 & 28.4 & $25-28^{\mathrm{f}}$ & n.a. \\
\hline Magnevist & $\begin{array}{c}\text { Gadopentetate } \\
\text { dimeglumine }\end{array}$ & Ionic linear & 22.5 & 18.4 & 0.4 & $5.6^{\mathrm{a}}-8^{\mathrm{c}}$ & $0.63^{\mathrm{a}, \mathrm{b}} ; 1.7^{1}$ \\
\hline \multirow[t]{3}{*}{ MulitHance } & $\begin{array}{l}\text { Gadobenate } \\
\text { dimeglumine }\end{array}$ & Ionic linear & 22.6 & 18.4 & 0 & $9-9.7$ & n.a. \\
\hline & & & \multirow{2}{*}{\multicolumn{3}{|c|}{$\begin{array}{l}\text { Stability-related parameter relevant for macrocyclic agents } \\
\text { Dissociation half-life (in hours at } \mathrm{pH} 1 \text { ) }\end{array}$}} & & \\
\hline & & & & & & & \\
\hline Gadovist & Gadobutrol & Macrocyclic & & $7.9^{\mathrm{d}}$ & & $15^{\mathrm{c}}$ & $2.8^{\mathrm{h}}-20^{\mathrm{i}}$ \\
\hline ProHance & Gadoteridol & Macrocyclic & & $2.0^{\mathrm{d}}$ & & $>10^{\mathrm{e}}$ & $0.79^{\mathrm{c}} ; 1.2^{\mathrm{h}}-2.7^{\mathrm{j}}$ \\
\hline Dotarem & $\begin{array}{l}\text { Gadoterate } \\
\text { dimeglumine }\end{array}$ & Macrocyclic & & $26.4^{\mathrm{d}}$ & & $18^{\mathrm{c}}$ & $0.1^{\mathrm{k}}$ \\
\hline
\end{tabular}

Data sources: ${ }^{\mathrm{a}}[8],{ }^{\mathrm{b}}[9],{ }^{\mathrm{c}}[9,10],{ }^{\mathrm{d}}[2],{ }^{\mathrm{e}}[11],{ }^{\mathrm{f}}[12],{ }^{\mathrm{g}}[13],{ }^{\mathrm{h}}$ calculated from [14], ${ }^{\mathrm{i}}$ calculated from [15], ${ }^{\mathrm{j}}$ calculated from [16, 17], ${ }^{\mathrm{k}}$ calculated from [18], calculated from [19] 


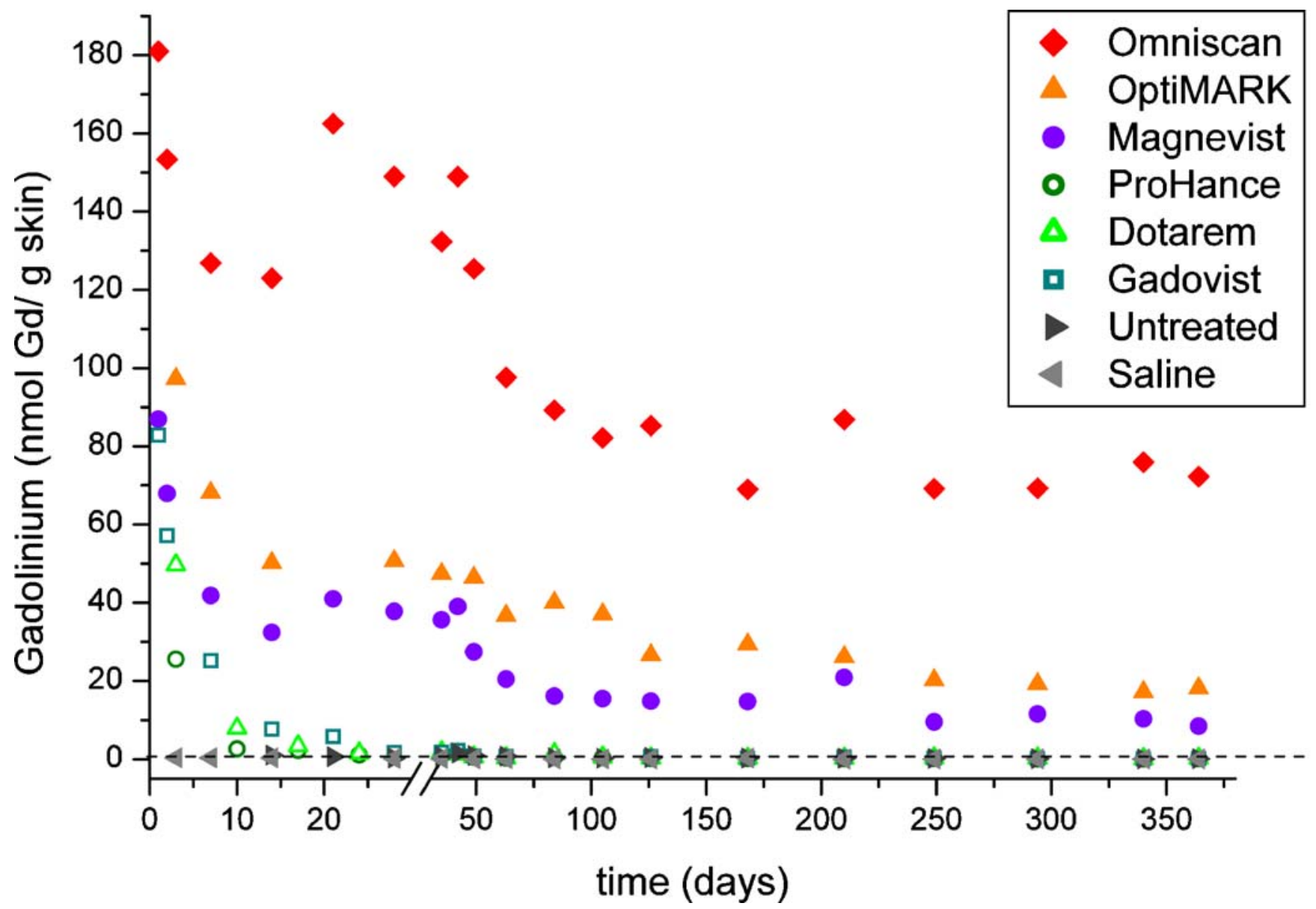

Fig. 1 Gadolinium concentration in the skin biopsies taken from animals treated with Omniscan (red diamonds), OptiMARK (orange triangles), Magnevist (violet dots), ProHance (green circles) Dotarem (green triangles), Gadovist (green squares) and control

injected once at a dose of $2.5 \mathrm{mmol} / \mathrm{kg}$ b.w. into the tail vein, and blood samples were taken from the cannulated carotid vein at various time-points p.i. $(1,3,5,10,15,30$, $60,90,120,180$ and $240 \mathrm{~min})$. The pharmacokinetic parameters were calculated with the help of WinNonlin (Pharsight Corporation, Montain View, Ca, USA), twocompartment model, $\mathrm{g}=1 / \mathrm{y}^{2}$.

\section{Gadolinium measurements}

The Gd concentrations in the skin samples and serum were determined by Inductively Coupled Plasma Mass Spectrometry (ICP-MS 7500a, Agilent, Waldbronn, Germany) by measuring the most abundant isotope ${ }^{158} \mathrm{Gd}$. Before drying at $90^{\circ} \mathrm{C}$, the skin samples $(7-22 \mathrm{mg})$ were mixed with $50 \mu \mathrm{l}$ of $1 \mu \mathrm{M} \mathrm{Tb}\left(\mathrm{NO}_{3}\right)_{3}$, serving as an internal standard. Afterwards $50 \mu \mathrm{l}$ concentrated $\mathrm{HNO}_{3}$ and $20 \mu \mathrm{l}$ $\mathrm{H}_{2} \mathrm{O}_{2}$ were added and heated to dissolve the tissue. The solution was filled up to $1 \mathrm{ml}$ with $\mathrm{H}_{2} \mathrm{O}$. The lower limit of animals (saline and untreated). The animals were injected on five consecutive days with $2.5 \mathrm{mmolGd} / \mathrm{kg}$ body weight (b.w.) per injection and the Gd concentration in the skin is given as nmolGd/g skin

quantification of the method is about $1 \mathrm{nmol} / 1$ or $0.05 \mathrm{nmol}$ $\mathrm{Gd} / \mathrm{g}$ skin $[20,21]$. It should be noted that this method cannot distinguish between chelated and unchelated $\mathrm{Gd}$.

\section{Statistical evaluation}

In order to calculate the areas under the curve (AUC), an exponential function was fitted to the data points by the help of the solver function of Excel (Microsoft Cooperation, Redmond, Wa, USA). Based in this function, the daily Gd exposure was calculated and summed up to the AUC for the investigated period. The AUCs were used to compare the treatment groups for which a control group (either saline or untreated) was available, i.e. for set 1 and set 3. The AUCs of the treatment groups were adjusted by using the difference in AUCs of the treatment group and the respective control.

Treatment differences were tested by a distribution-free Kruskal-Wallis one-way analysis of variance on ranks. 
Overall differences of the medians were tested by the Kruskal-Wallis test, whereas pairwise differences were tested by Dunn's test. This distribution-free multiple comparison test does not need the assumption of normality and tests pairs of medians following the Kruskal-Wallis test. The significance level is adjusted on the basis of comparisons to keep the two-sided significance level of 5\% for each experiment. Instead of means, this test uses average ranks. Calculations were performed using NCSS 2007 (NCSS, Kaysville, Ut, USA).

\section{Results}

For several weeks after the last injection, the Gd concentration in the skin decreased substantially in all treatment groups. About 60 days after treatment with linear GBCAs, a plateau phase for $\mathrm{Gd}$ concentration was observed. Following this phase, the Gd level decreased only marginally during the next 304 days (Fig. 1). After treatment with the macrocyclic GBCAs, the Gd values in skin tissue returned to the same range as that observed in the control animals from about day 24 post-treatment onwards. It should be noted that we could detect small amounts of Gd in the skin of control animals, most obvious in the skin of the untreated animals (set 1). No macroscopic skin changes were observed in any treatment group during the entire course of the experiment.

The following are detailed results of all treatment groups for selected time-points post-treatment, i.e. about 1 month and 1 year p.i. (also see Table 2).

On day 35 p.i., the highest amount of Gd was observed after treatment with the non-ionic linear GBCAs Omniscan $(132 \pm 23 \mathrm{nmolGd} / \mathrm{g}$ skin) and OptiMARK (47 \pm $5 \mathrm{nmolGd} / \mathrm{g}$ skin). Lower Gd values in the skin were measured in animals treated with the ionic linear GBCAs Magnevist $(36 \pm 6 \mathrm{nmolGd} / \mathrm{g}$ skin) and MultiHance $(7 \pm$ $1 \mathrm{nmolGd} / \mathrm{g}$ skin). Even lower Gd values were observed in biopsies taken from animals injected with the macrocyclic GBCAs, ProHance ( $1 \pm 1 \mathrm{nmolGd} / \mathrm{g}$ skin), Dotarem $(2 \pm$ $1 \mathrm{nmolGd} / \mathrm{g}$ skin) and Gadovist $(2 \pm 1 \mathrm{nmolGd} / \mathrm{g}$ skin $)$ (Fig. 2a).

On day 364 p.i., the highest amount of Gd was, again, observed after treatment with the non-ionic linear GBCAs Omniscan (72 $\pm 12 \mathrm{nmolGd} / \mathrm{g}$ skin) and OptiMARK (18 \pm $5 \mathrm{nmolGd} / \mathrm{g}$ skin). Lower Gd values in the skin were again measured in animals treated with the ionic linear GBCAs Magnevist ( $9 \pm 2 \mathrm{nmolGd} / \mathrm{g}$ skin) and MultiHance (1.4 \pm $0.4 \mathrm{nmolGd} / \mathrm{g}$ skin). For biopsies taken from animals treated with the macrocyclic GBCAs ProHance $(0.08 \pm$ $0.02 \mathrm{nmolGd} / \mathrm{g}$ skin $)$, Dotarem $(0.22 \pm 0.17 \mathrm{nmolGd} / \mathrm{g}$ skin) and Gadovist $(0.06 \pm 0.03 \mathrm{nmolGd} / \mathrm{g}$ skin $)$, the $\mathrm{Gd}$ values were in the same low range and close to the detection limit of the ICP-method as for untreated control animals $(0.06 \pm 0.03 \mathrm{nmolGd} / \mathrm{g}$ skin $)$ and saline treated animals $(0.18 \pm 0.07 \mathrm{nmolGd} / \mathrm{g}$ skin) (Fig. $2 \mathrm{~d})$. For the $\mathrm{Gd}$ values measured 2 and 6 months p.i., please refer to Fig. $2 b$ and $\mathrm{c}$.

Statistical evaluation of the Gd concentration timecourse in the skin tissue of rats of the treatment groups evaluated in set 1 (i.e. Omniscan, Magnevist, Gadovist, untreated) and set 3 (OptiMARK and saline) revealed clear differences between the various GBCAs. Figure 3 depicts the results of set 1 as box plots. No elevated Gd values could be detected in the skin tissue of rats treated with the macrocyclic compound, Gadovist, from day 24 onwards. However, after treatment with the three linear GBCAs Omniscan, OptiMARK and Magnevist elevated Gd levels in skin tissue were observed for the entire experimental observation time, with the non-ionic linear

Table 2 Summary of key results on gadolinium retention in the rat skin

\begin{tabular}{|c|c|c|c|c|c|c|}
\hline Trade name & $\begin{array}{l}\text { Structural } \\
\text { class }\end{array}$ & $\begin{array}{l}\text { Blood } \mathrm{AUC}^{\mathrm{a}} \\
(\mathrm{mmol} / \mathrm{l} \times \mathrm{min})\end{array}$ & $\begin{array}{l}\text { Gadolinium } \\
\text { concentration on day } \\
364 \text { p.i. (nmol/g skin) }\end{array}$ & $\begin{array}{l}\text { Percent of dose } \\
\text { found in the skin } \\
\text { at day } 364 \text { p.i. }\end{array}$ & $\begin{array}{l}\text { Total exposure of the } \\
\text { skin to Gd (molGd/g } \\
\text { skin } \times 368 \text { days) }\end{array}$ & $\begin{array}{l}\text { Exposure of the skin to } \mathrm{Gd} \\
\text { during the retention period } \\
(\mathrm{molGd} / \mathrm{g} \text { skin } \times 301 \text { days })\end{array}$ \\
\hline Omniscan & Non-ionic linear & 191 & $72.2 \pm 11.9$ & $\sim 0.0809 \%$ & $32.5 \pm 4.4$ & $24.4 \pm 3.5$ \\
\hline OptiMARK & Non-ionic linear & n.d. & $18.2 \pm 4.8$ & $\sim 0.0204 \%$ & $9.4 \pm 0.9$ & $7.2 \pm 0.8$ \\
\hline Magnevist & Ionic linear & 200 & $8.5 \pm 1.5$ & $\sim 0.0095 \%$ & $7.1 \pm 0.4$ & $4.7 \pm 0.3$ \\
\hline MultiHance & Ionic linear & $146^{\mathrm{b}}$ & $1.4 \pm 0.4$ & $\sim 0.0016 \%$ & $2.2 \pm 0.3$ & $1.5 \pm 0.2$ \\
\hline Gadovist & Macrocyclic & 184 & $0.06 \pm-0.03$ & $\sim 0.00007 \%$ & $1.0 \pm 0.1$ & $0.2 \pm 0.1$ \\
\hline ProHance & Macrocyclic & n.d. & $0.08 \pm 0.02$ & $\sim 0.00009 \%$ & $0.6 \pm 0.1$ & $0.1 \pm 0.05$ \\
\hline Dotarem & Macrocyclic & n.d. & $0.22 \pm 0.17$ & $\sim 0.00024 \%$ & $0.9 \pm 0.2$ & $0.2 \pm 0.08$ \\
\hline Untreated & - & - & $0.06 \pm 0.03$ & - & $0.1 \pm 0.02$ & $0.1 \pm 0.03$ \\
\hline Saline & - & - & $0.18 \pm 0.07$ & - & $0.04 \pm 0.01$ & $0.03 \pm 0.01$ \\
\hline
\end{tabular}

${ }^{\mathrm{a}}$ Exposure of the blood of Han-Wistar rats after the administration of dose of $2.5 \mathrm{mmol} / \mathrm{kg}$

${ }^{b}$ Note that MultiHance is excreted up to $50 \%$ by the hepatobiliary system in rats causing a $30 \%$ reduced exposure (AUC), whereas in humans hepatobiliary elimination is only $1-4 \%$ 
a

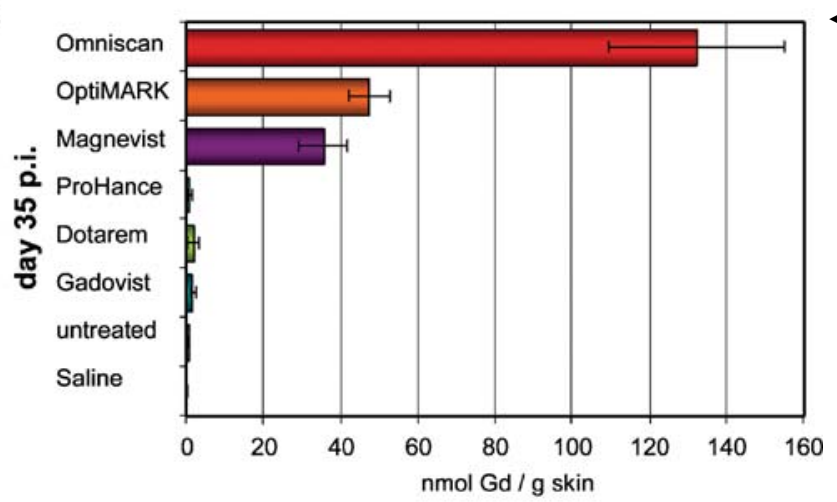

b

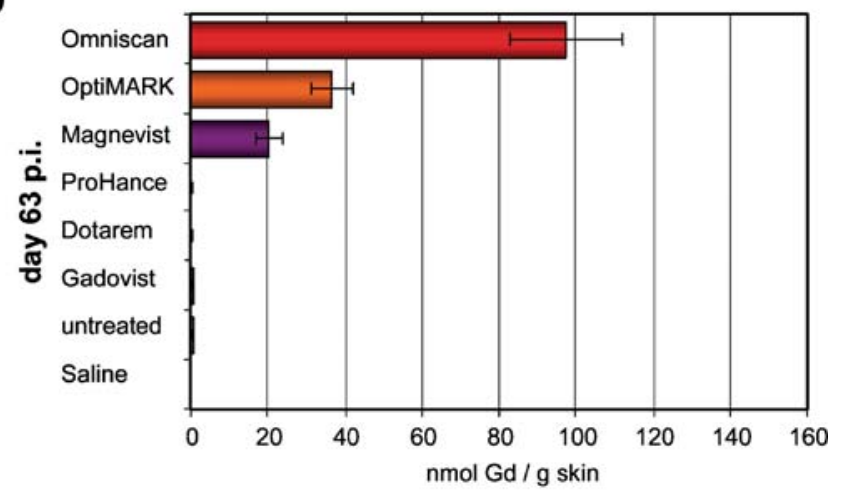

C

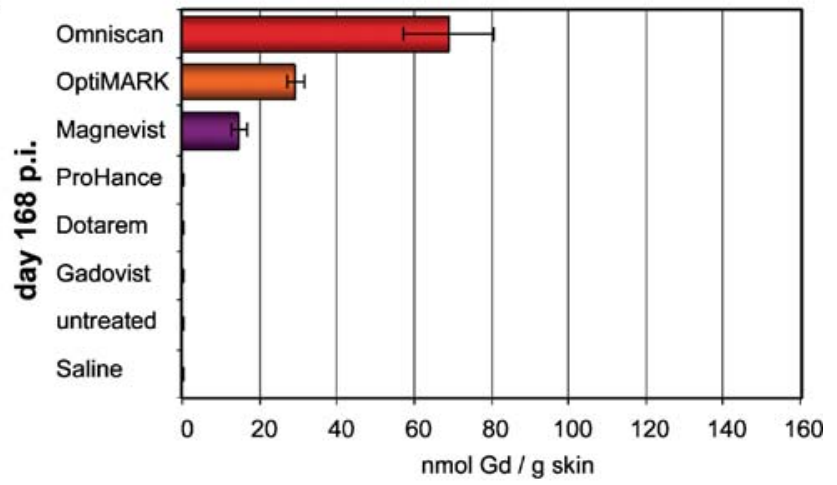

d

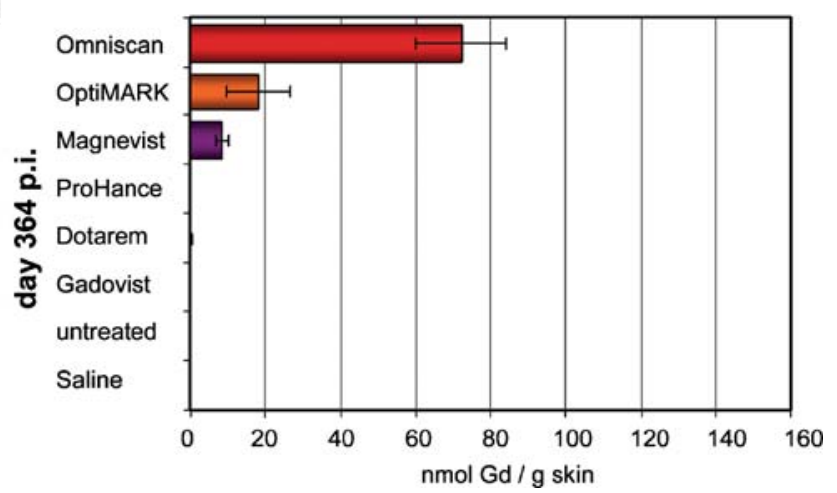

Fig. 2 a-c Comparison of gadolinium concentration in the skin biopsies taken from animals on day 35, 63, 168 and 364 p.i. after treatment with Omniscan, OptiMARK, Magnevist, Dotarem, ProHance and Gadovist. The animals were injected on five consecutive days with $2.5 \mathrm{mmolGd} / \mathrm{kg}$ b.w. per injection and the Gd concentration in the skin is given as $\mathrm{nmolGd} / \mathrm{g}$ skin

compound Omniscan, showing statistically significantly higher Gd levels compared with the ionic linear compound Magnevist.

To estimate the Gd exposure to the skin, we calculated the AUC of the Gd values for the total observation period (until 364 days p.i., including the injection phase), as well as for the long-term retention period ('plateau phase') (63364 days p.i.) (Fig. 4). Again, the highest total exposure was observed after treatment with the non-ionic linear GBCAs Omniscan $(32.5 \pm 4.4 \mathrm{molGd} / \mathrm{g}$ skin $\times 368$ days and $24.4 \pm 3.5 \mathrm{molGd} / \mathrm{g}$ skin $\times 301$ days for the long-term retention period $)$ and OptiMARK $(9.4 \pm 0.9 \mathrm{molGd} / \mathrm{g}$ skin $\times$ 368 days for the total $\mathrm{Gd}$ exposure of the skin and $7.2 \pm$ $0.8 \mathrm{molGd} / \mathrm{g}$ skin $\times 301$ days for the long-term retention period). Lower exposure of the skin to Gd was observed after treatment with the ionic linear GBCAs Magnevist $(7.1 \pm 0.4 \mathrm{molGd} / \mathrm{g}$ skin $\times 368$ days for the total $\mathrm{Gd}$ exposure of the skin and $4.7 \pm 0.3 \mathrm{molGd} / \mathrm{g}$ skin $\times 301$ days for the long-term retention period) and MultiHance (2.2 \pm $0.3 \mathrm{molGd} / \mathrm{g}$ skin $\times 368$ days for the total Gd exposure of the skin and $1.5 \pm 0.2 \mathrm{molGd} / \mathrm{g}$ skin $\times 301$ days for the longterm retention period).

For all macrocyclic agents total Gd exposure in the skin (wash-out phase plus long-term retention phase) was higher than the saline and untreated controls. For the long-term retention period, however, exposure levels were in the same range as the controls (Fig. 4 and Table 2).

In general, the lowest values for the total exposure and for the exposure in the long-term retention period was observed after treatment with the macrocyclic GBCAs. Higher values were observed after treatment with the ionic linear GBCAs and the highest values were observed after treatment with the non-ionic linear GBCAs. Those differences were significant between treatment with macrocyclic GBCA Gadovist and the treatment with the non-ionic linear GBCAs Omniscan and OptiMARK. Additionally, those differences were also significant between treatment with the non-ionic linear GBCA Omniscan and treatment with the ionic linear GBCA Magnevist and macrocyclic GBCA Gadovist treatment. No statistical differences were found for the total exposure and the long-term retention period between any other two treatment groups.

\section{Discussion}

The aim of the study was to determine the elimination course and a potential long-term retention of $\mathrm{Gd}$ in the skin of rats after administration of different marketed GBCAs. 

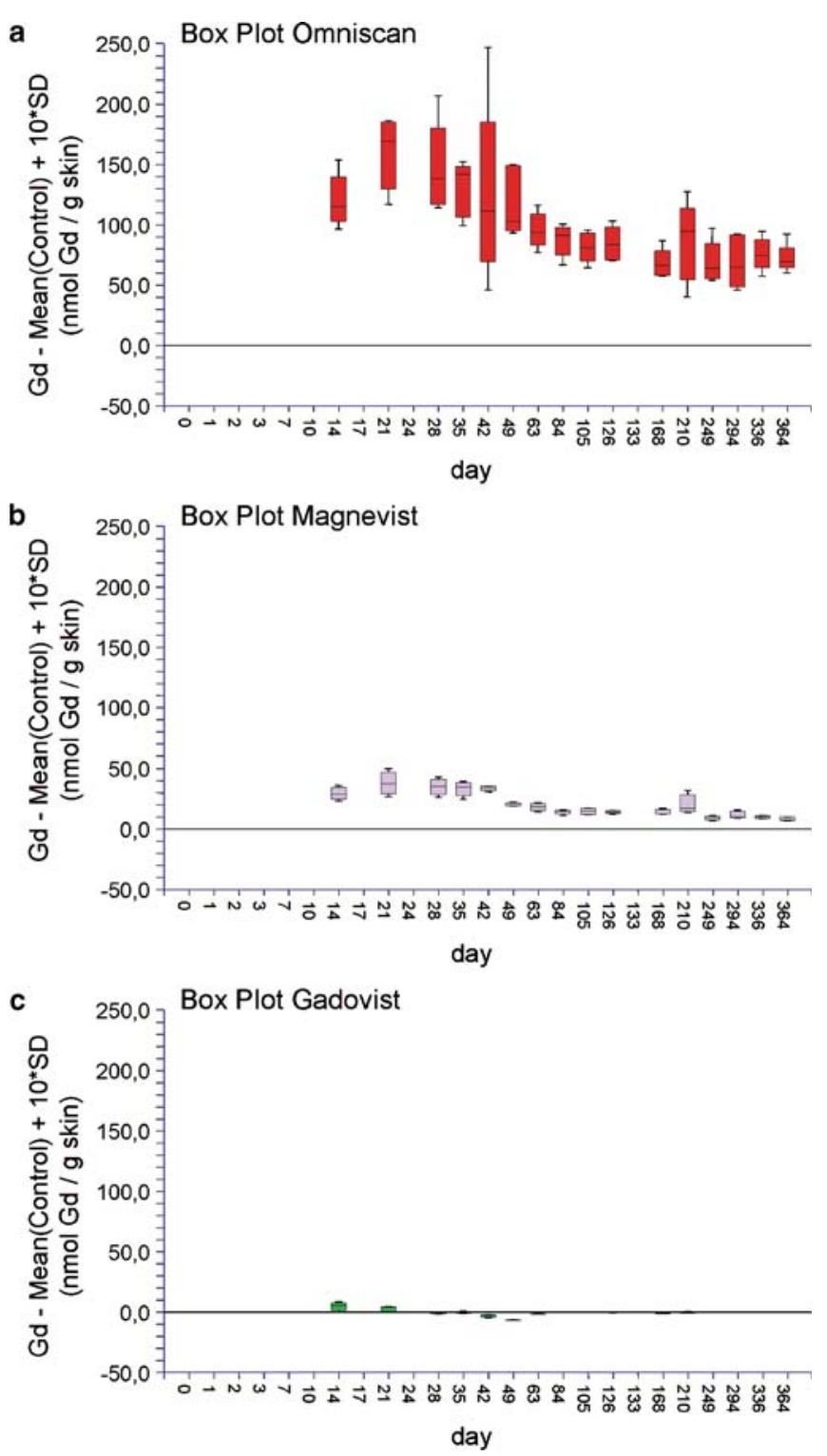

Fig. 3 Gadolinium concentration in the skin biopsies taken from animals treated with three different classes of GBCAs. The boxplots display the Gd content in the skin of treated animals after subtraction of the average Gd content of skin tissue of the respective control animals on the respective day and ten-times the corresponding standard deviation (SD). The null-line is set at the average value of Gd content of the skin of control animals plus ten-times the SD. The animals were injected on five consecutive days with Omniscan (upper panel), Magnevist (middle panel) and Gadovist (lower panel) at a dose of $2.5 \mathrm{mmolGd} / \mathrm{kg}$ b.w. per injection and the $\mathrm{Gd}$ concentration in the skin is given as $\mathrm{nmolGd} / \mathrm{g}$ skin

Regarding the elimination of Gd in the rat skin, in the immediate phase (wash-out phase), starting after the injection and lasting for several days (macrocyclic GBCAs) to weeks (linear GBCAs), the Gd concentration in the skin decreased considerably. This suggests that the Gd eliminated in this phase is readily eliminable, i.e. most likely water soluble and intact GBCA.
In the second phase (plateau phase), a steady-state level of Gd was observed, which decreased only minimally over time. For the linear GBCAs we observed Gd levels well above the level observed in control animals for up to a year after the last Gd injection (most pronounced in animals treated with Omniscan). For the macrocyclic GBCAs we observed the same low Gd levels in the skin as in control animals.

It has to be noted that we detected minor amounts of Gd in skin tissue of control animals, especially in set 1 . This might be attributed to a potential Gd contamination in our laboratory. The level of contamination was in the same range as observed after administration of the macrocyclics, but well below the amount of Gd observed after administration of linear GBCAs

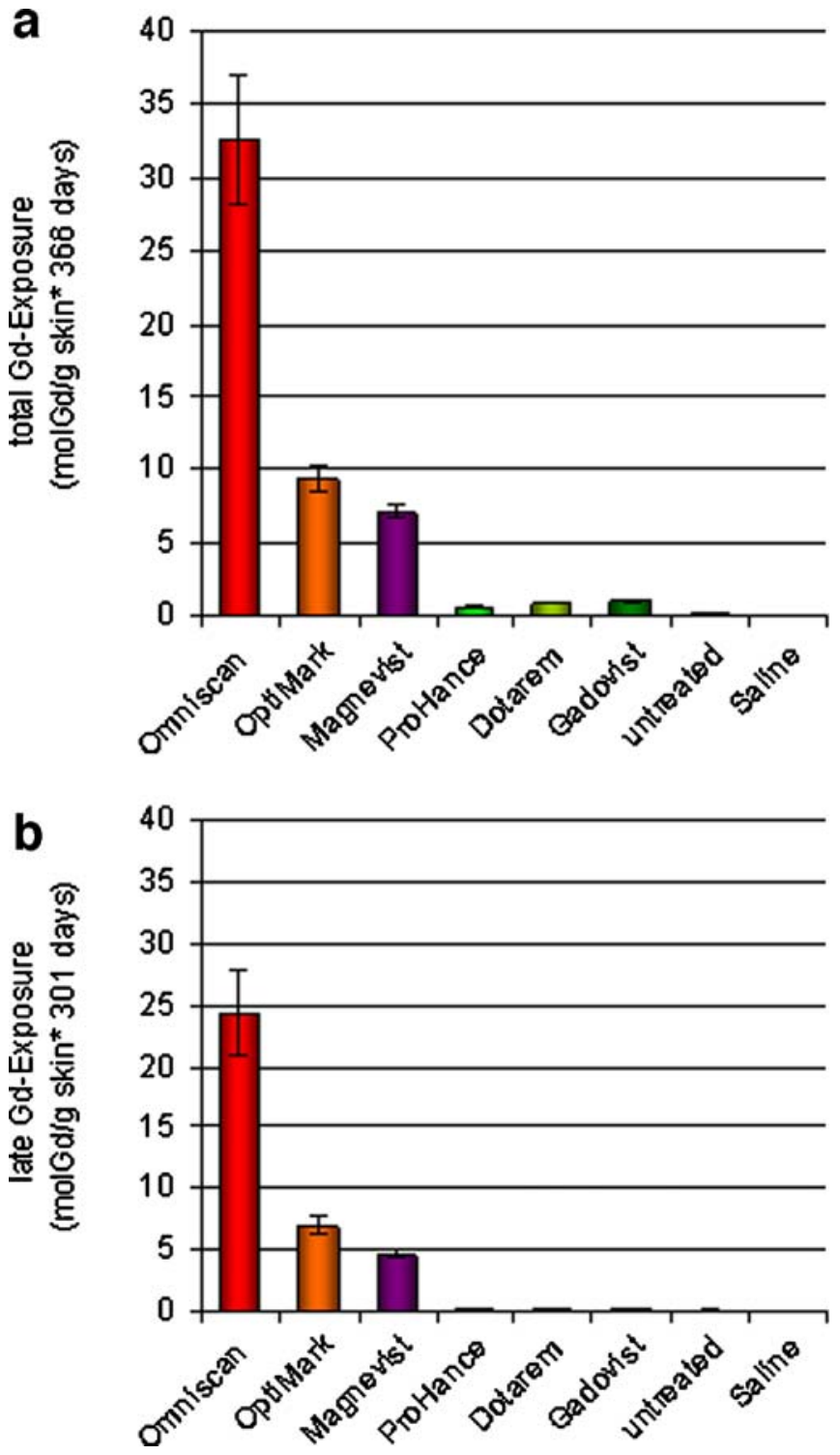

Fig. 4 Exposure of the skin to gadolinium (a) during the whole experiment and (b) during the retention phase. The animals were injected on five consecutive days with $2.5 \mathrm{mmolGd} / \mathrm{kg}$ b.w. per injection 
(Table 2). Those differences in background values most likely also explain the minor differences in the Gd concentration and exposure of the skin to Gd observed after treatment with the different macrocyclic GBCAs.

The fact that the observed Gd was retained for such a long period in the skin of treated animals leads us to hypothesize that the Gd may exist in a water-insoluble state, which would make it less subject to elimination. But, as noted before, the methods used in this experiment to measure Gd levels could not distinguish between the various forms of $\mathrm{Gd}$. Long-term retention of $\mathrm{Gd}$ in tissues has also been reported from NSF patients after multiple Gd-enhanced MRI investigations [22].

The time-course of the Gd concentrations in the skin (Fig. 1) and the exposure of the skin to Gd correlate with the stability of the GBCAs.

Based on kinetic considerations, the macrocyclic GBCAs are the most stable. In-vitro serum stability experiments could not detect any Gd release from macrocyclic agents within 15 days [23]. In the present experiment, all three macrocyclic GBCAs showed no long-term Gd retention in the skin tissue of treated rats that exceeded the level observed in control animals. All three macrocyclic agents showed virtually identical patterns of Gd elimination from the skin tissue of the study animals, reinforcing the notion that the minute in-vitro stability differences between the macrocyclic GBCAs are extremely unlikely to result in relevant differences in-vivo [3].

The ionic linear GBCAs are more stable than the nonionic linear GBCAs [3], but both may release Gd in-vivo under certain circumstances. However, based on the results of in-vitro stability experiments in human serum [23] and buffered saline solution [24], any such release is expected to be significantly less with ionic linear agents than with non-ionic linear agents. Likewise, in our experiment, the Gd values observed on day 364 after the last injection of the ionic linear compound Magnevist were about ninetimes lower compared with the treatment with the nonionic linear compound Omniscan.

The non-ionic linear GBCAs have the highest level of Gd in the skin tissue of study animals in the plateau phase. Still, only a minute proportion of the injected Gd actually is retained in the body. The Gd values observed in the skin on day 364 p.i. of the Omniscan-treated animals correspond to about $0.081 \%$ of the total dose of Omniscan administered. This small fraction of Gd may explain why earlier pharmacokinetic studies failed to detect any Gd retention [25]. The difference in retained Gd between Omniscan and OptiMARK treatment may be related to the difference in the amount of excess ligand in the formulation of these two GBCAs [26].

While the difference in $\mathrm{Gd}$ retention is qualitatively correlated to the stability of the respective GBCA, no such correlation exists with the selectivity of the respective ligand to Gd over other metal ions or the acute toxicity of GBCAs, as indicated by $\mathrm{LD}_{50}$ values (Table 1). Such a hypothesis has been discussed previously [8, 9]. In contrast, our study suggests the importance of the stability of GBCAs to minimize Gd retention and to prevent the potential release of $\mathrm{Gd}$.

This study has certain limitations. The experimental setting can be used to evaluate the concentration of $\mathrm{Gd}$ retained in rats after administration of different GBCAs using the dosing regimen employed in this study. However, due to significant differences in the pharmacokinetic properties of MultiHance in rats and humans, it is not possible to make valid, clinically relevant comparisons between MultiHance and other GBCAs using this model. Furthermore, as with all animal studies, caution must be exercised when extrapolating results to humans.

As the employed method for measuring Gd cannot distinguish between chelated and unchelated Gd, it is not possible to determine whether the retained Gd observed in the plateau phases after application of linear agents is chelated or unchelated. Furthermore, the study cannot answer whether the long-term retention of small amounts of the originally applied Gd doses plays any role in or contributes to the fibrosis observed in skin samples of NSF patients.

However, if Gd release plays a role in the onset of NSF, the data from this preclinical study suggest that there are potential differences in the risk profile for the different marketed GBCAs, with non-ionic linear agents possibly presenting a higher risk than the macrocyclic agents.

Acknowledgements This study was funded by Bayer Schering Pharma AG. The authors would like to thank Christiane Pering and Thomas Steger-Hartmann for the critical reading of the manuscript and Ines Heinzelmann, Stefanie Runge, and Andrea Baumgart for their excellent technical assistance. The authors would like to thank Carsten Schwenke, SCO: SSiS, Berlin, Germany, for his consultancy in statistics.

Open Access This article is distributed under the terms of the Creative Commons Attribution Noncommercial License which permits any noncommercial use, distribution, and reproduction in any medium, provided the original author(s) and source are credited.

\section{References}

1. Caravan P, Ellison JJ, Mcmurry TJ, Lauffer RB (1999) Gadolinium(III) Chelates as MRI contrast agents: structure, dynamics, and applications. Chem Rev 99:2293-2352
2. Port M, Idée JM, Medina C, Robic C et al (2008) Efficiency, thermodynamic and kinetic stability of marketed gadolinium chelates and their possible clinical consequences: a critical review. Biometals 21(4):469-490, Aug
3. Schmitt-Willich H (2007) Stability of linear and macrocyclic gadolinium based contrast agents. Br J Radiol 80:581-582 author reply 584-585 
4. Grobner T (2006) Gadoliniuma specific trigger for the development of nephrogenic fibrosing dermopathy and nephrogenic systemic fibrosis? Nephrol Dial Transplant 21:3604-3605

5. Marckmann P, Skov L, Rossen K et al (2006) Nephrogenic systemic fibrosis: suspected causative role of gadodiamide used for contrast-enhanced magnetic resonance imaging. J Am Soc Nephrol 17:2359-2362

6. Sieber MA, Pietsch H, Walter J, Haider W, Frenzel T, Weinmann H-J (2008) A preclinical study to investigate the development of Nephrogenic Systemic Fibrosis: a possible role for gadolinium-based contrast media. Inv Rad 43:65-75

7. Sieber MA, Lengsfeld P, Frenzel T, et al (2008) Preclinical investigation to compare different gadolinium-based contrast agents regarding their propensity to release gadolinium in vivo and to trigger nephrogenic systemic fibrosis-like lesions. Eur Radiol 18:21642173

8. Cacheris WP, Quay SC, Rocklage SM (1990) The relationship between thermodynamics and the toxicity of gadolinium complexes. Magn Reson Imaging 8:467-481

9. Mann JS (1993) Stability of gadolinium complexes in vitro and in vivo. J Comput Assist Tomogr 17(Suppl 1):S19-S23

10. Weinmann HJ, Press WR, Gries H (1990) Tolerance of extracellular contrast agents for magnetic resonance imaging. Invest Radiol 25(Suppl 1):S49-S50

11. Soltys RA (1992) Summary of preclinical safety evaluation of gadoteridol injection. Invest Radiol 27(Suppl 1):S7-S11
12. Wible JH Jr, Troup CM, Hynes MR et al (2001) Toxicological assessment of gadoversetamide injection (OptiMARK), a new contrast-enhancement agent for use in magnetic resonance imaging. Invest Radiol 36:401-412

13. Puttagunta NR, Gibby WA, Puttagunta VL (1996) Comparative transmetallation kinetics and thermodynamic stability of gadolinium-DTPA bisglucosamide and other magnetic resonance imaging contrast media. Invest Radiol 31:619-624

14. Bianchi A, Calabi L, Giorgi C et al (2000) Thermodynamic and structural properties of $\mathrm{Gd} 3+$ complexes with functionalized macrocyclic ligands based upon 1,4,7,10-tetraazacyclododecane. J Chem Soc Dalton Trans:627-705

15. Clarke ET, Martell AE (1991) Stabilities of trivalent metal ion complexes of the tetraacetate derivatives of 12-, 13and 14-membered tetraazamacrocycles. Inorg Chim Acta 37-49

16. Kumar K, Chang A, Francesconi LC et al (1994) Synthesis, stability, and structure of gadolinium(III) and yttrium (III) macrocyclic poly(amino carboxylates). Inorg Chem 33:3567-3575

17. Kumar K, Tweedle MF, Malley MF, Gougoutasi JZ (1995) Synthesis, stability, and crystal structure studies of some $\mathrm{Ca} 2+, \mathrm{Cu} 2+$, and $\mathrm{Zn} 2+$ complexes of macrocyclic polyamino carboxylates. Inorg Chem 34:64726480

18. Tóth É, Király R, Platzek J, Radüchel B, Brücher E (1996) Equilibrium and kinetic studies on complexes of 10-[2,3-dihydroxy-(1-hydroxymethyl)propyl]-1,4,7,10-tetraazacyclododecane1,4,7-triacetate. Inorganica Chimica Acta 249:191-199

19. Schmitt-Willich H, Brehm M, Ewers CL et al (1999) Synthesis and physicochemical characterization of a new gadolinium chelate: the liver-specific magnetic resonance imaging contrast agent Gd-EOB-DTPA. Inorg Chem 38:1134-1144
20. Skelly Frame EM, Uzgiris EE (1998) Gadolinium determination in tissue samples by inductively coupled plasma mass spectrometry and inductively coupled plasma atomic emission spectrometry in evaluation of the action of magnetic resonance imaging contrast agents. Analyst 123:675-679

21. Thomas R (2001) A beginner's guide to ICP-MS. CRC Press, London

22. Thakral C, Abraham JL (2007) Automated scanning electron microscopy and $\mathrm{x}$-ray microanalysis for in situ quantification of gadolinium deposits in skin. J Electron Microsc (Tokyo) 56:181-187

23. Frenzel T, Lengsfeld P, Schirmer H, Hütter J, Weinmann HJ (2008) Stability of gadolinium-based magnetic resonance imaging contrast agents in human serum at 37 degrees C. Invest Radiol 43:817-828

24. Laurent S, Elst LV, Muller RN (2006) Comparative study of the physicochemical properties of six clinical low molecular weight gadolinium contrast agents. Contrast Media Mol Imaging 1:128-137

25. Reinton V, Berg KJ, Savaland M, Andrew E, Normann PT, Rootwelt K (1994) Pharmacokinetics of gadodiamdie injection in patients with moderately impaired renal function. Acad Radiol 1:S56-S61

26. Sieber MA, Lengsfeld $P$, Walter J et al (2008) Gadolinium-based contrast agents and their potential role in the pathogenesis of nephrogenic systemic fibrosis: the role of excess ligand. $\mathrm{J}$ Magn Reson Imaging 27:955-962 